\title{
The Chlorophyll Catabolite, Pheophorbide a, Confers Predation Resistance in a Larval Tortoise Beetle Shield Defense
}

\author{
Fredric V. Vencl • Nélida E. Gómez • Kerstin Ploss • \\ Wilhelm Boland
}

Received: 28 October 2008 /Revised: 1 December 2008 /Accepted: 4 December 2008 /Published online: 7 January 2009

(C) Springer Science + Business Media, LLC 2008

\begin{abstract}
Larval insect herbivores feeding externally on leaves are vulnerable to numerous and varied enemies. Larvae of the Neotropical herbivore, Chelymorpha alternans (Chrysomelidae:Cassidinae), possess shields made of cast skins and feces, which can be aimed and waved at attacking enemies. Prior work with $C$. alternans feeding on Merremia umbellata (Convolvulaceae) showed that shields offered protection from generalist predators, and polar compounds were implicated. This study used a ubiquitous ant predator, Azteca lacrymosa, in field bioassays to determine the chemical constitution of the defense. We confirmed that intact shields do protect larvae and that methanol-water leaching significantly reduced shield effectiveness. Liquid chromatography-mass spectrometry (LCMS) of the methanolic shield extract revealed two peaks at $20.18 \mathrm{~min}$ and $21.97 \mathrm{~min}$, both with a molecular ion at $\mathrm{m} / \mathrm{z}$ 593.4, and a strong UV absorption around $409 \mathrm{~nm}$, suggesting a porphyrin-type compound. LC-MS analysis of a commercial standard confirmed pheophorbide $a(\mathrm{Ph} a)$ identity. C. alternans shields contained more than $100 \mu \mathrm{g}$ $\mathrm{Ph} a$ per shield. Shields leached with methanol-water did not deter ants. Methanol-water-leached shields enhanced
\end{abstract}

\author{
F. V. Vencl $(\bowtie)$ \\ Department of Ecology and Evolution, Stony Brook University, \\ Stony Brook, NY 11794-5245, USA \\ e-mail: fvencl@life.bio.sunysb.edu \\ F. V. Vencl · N. E. Gómez \\ The Smithsonian Tropical Research Institute, \\ P.O. Box 2072, Ancón, \\ Balboa, Republic of Panamá \\ K. Ploss $\cdot$ W. Boland \\ Max-Planck-Institut für Chemische Ökologie, \\ Hans-Knöll-Str. 8, \\ 07745 Jena, Germany
}

with $3 \mu \mathrm{g}$ of $\mathrm{Ph} a$ were more deterrent than larvae with solvent-leached shields, while those with $5 \mu \mathrm{g}$ additional $\mathrm{Ph} a$ provided slightly less deterrence than larvae with intact shields. Solvent-leached shields with $10 \mu \mathrm{g}$ added $\mathrm{Ph} a$ were comparable to intact shields, even though the $\mathrm{Ph} a$ concentration was less than $10 \%$ of its natural concentration. Our findings are the first to assign an ecological role for a chlorophyll catabolite as a deterrent in an insect defense.

Keywords Chrysomelidae $\cdot$ Cassidinae $\cdot$ Azteca . Chelymorpha $\cdot$ porphyrin $\cdot$ Merremia $\cdot$ Insect defense

\section{Introduction}

More so than for agile insect adults, flightless, soft-bodied larvae are exposed to numerous natural enemies as they feed openly on leaf surfaces. Consequently, folivorous larvae suffer the highest mortality rates, frequently approaching $90 \%$, among the respective developmental stages (Gross 1993; Hunter 2000; Zalucki et al. 2002). In response, larvae have evolved an astonishing variety of physical barriers, such as setae, spines, and webs, as well as chemical barriers, such as glandular exudates and fore and aft enteric discharges that function to reduce vulnerability to natural enemies (Whitman et al. 1990; Evans and Schmidt 1991; Ruxton et al. 2004 and references therein). Many of these strategies are supplemented by behaviors that enhance their effectiveness (Gross 1993; Stamp and Casey 1993 and references therein). Among the most bizarre of these characters is fecal retention. Although rare among insects generally (Weiss 2006), fecal retention can be found in a restricted number of leaf beetle (Chrysomelidae) and weevil (Curculionidae) lineages with exophytic larvae. Within the chrysomelids, however, fecal retention is 
Fig. 1 Larva of a C. alternans showing the fecal shield (arrow) above the larval dorsum (bar= $2 \mathrm{~mm})$; b the A. lacrymosa nest (upper arrow) and bioassay arena (lower arrow)
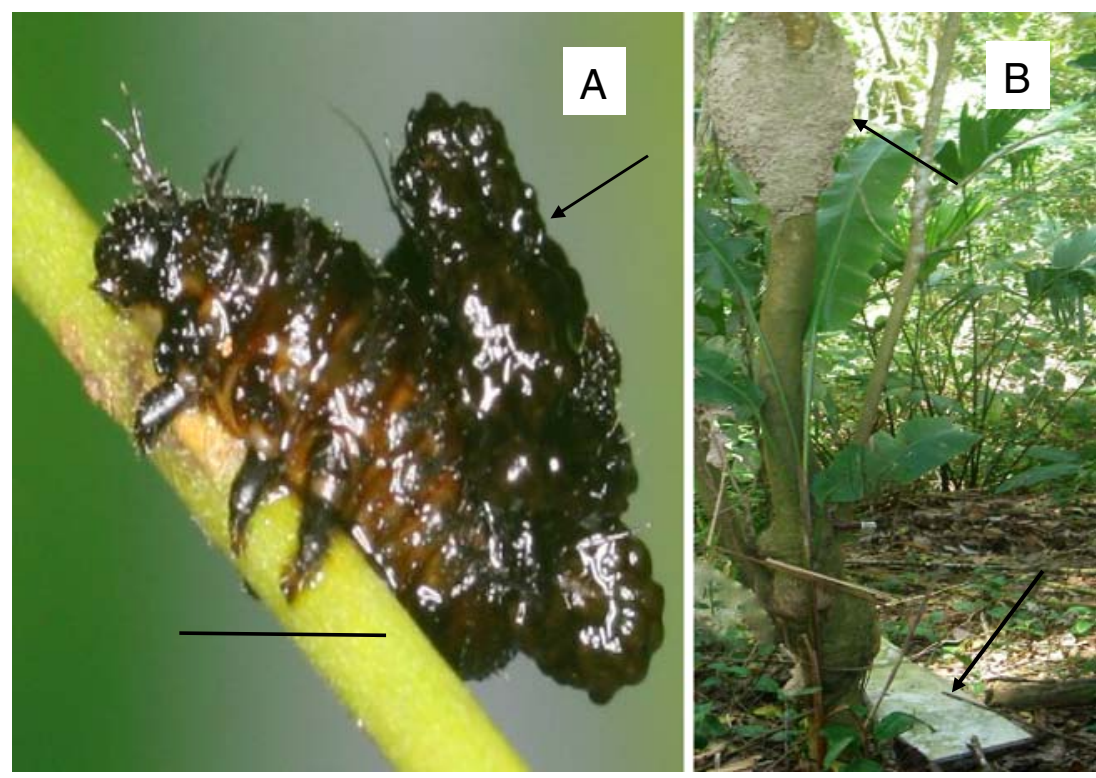

common. Nearly $20 \%$ of the 35,000 described leaf beetle species have some form of larval fecal retention (Vencl et al. 1999). For example, there are three different approaches to using feces for larval defense in the Chrysomelidae: the unstructured dorsal piles in Criocerinae, the scatoshells in the Camptosomata group, and the elaborate dorsal annexes constructed by the Cassidinae.

Instead of ridding themselves of their digestive wastes, the larvae of tortoise beetles (Cassidinae) have the peculiar habit of voiding feces onto their backs, where it accumulates to form a coating or shield. Shields do not rest passively on the dorsum. They have a solid infrastructure formed by the accumulation of molted skins, which is itself attached to a highly movable, forked caudal process located on the penultimate abdominal segment. Adding to the shield system is a novel, telescoping anus that precisely applies feces to the shield armature (see Vencl et al. 1999; Fig. 1a). Fresh, wet feces may be the most deterrent or repellent part of the elaborate shield structure, and the unusual anal application mechanism maintains the freshest fecal material right at the periphery of the shield where predators are most likely to make initial contact (Vencl, personal observation). Held like parasols above the larvae, shields can be aimed and waved in any direction. Although possibly affording protection against deleterious abiotic factors, tortoise beetle shields have been shown to function as both physical (Eisner et al. 1967; Olmstead and Denno 1993; Eisner and Eisner 2000) and as chemical defenses against natural enemies (Vencl et al. 1999; Müller and Hilker 2004; Gómez et al. 1999; Nogueira-de-Sá and Trigo 2002, 2005).

Larvae of the tortoise beetle, Chelymorpha alternans, possess fecal shields that previously have been shown to thwart attacking bugs and ants (Fig. 1a). Although the role of defensive behaviors, such as shield waving and escape, may have contributed to larval survival, the effectiveness of $C$. alternans shields appeared to be due mainly to a chemical component residing in the shield's feces. For example, when larvae lacking recourse to defense behaviors had their shields leached with methanol $(\mathrm{MeOH})$, their capacity to withstand capture by ants was reduced significantly, compared to both larvae with water-leached and larvae with intact shields. This finding indicated that this species relies heavily on $\mathrm{MeOH}$-soluble components to mount an effective defense (Vencl et al. 2005). Although shields in some tortoise beetle species depend on host-derived terpenes, phenolics, alkaloids, or saponins, the shields of other species require fatty acids or phytol to function effectively as defenses (reviewed by Müller and Hilker 2004). However, neither the chemical constitution nor the origin of C. alternans' shield chemistry is known.

Here, we investigated how C. alternans larvae chemically enhance their remarkable shield structures. We wanted to know what compounds might be responsible for shield effectiveness, whether chemically denuded shields could confer resistance against one of the larva's most important enemies, if larvae were somehow able to sequester repellent or deterrent precursors from their diet, or if they were capable of endogenously synthesizing them. Based on the previous study mentioned above, we focused on the bioactivity of the methanolic extract of $C$. alternans shields, which appeared to be responsible for reduced larval vulnerability to predation.

\section{Materials and Methods}

Beetle Collection and Husbandry We collected C. alternans larvae from Merremia umbellata (Convolvulaceae) 
near Gamboa, Colon Province, Republic of Panamá $\left(9^{\circ} 06^{\prime}\right.$ $\left.\mathrm{N}, 79^{\circ} 41^{\prime} \mathrm{W}\right)$. Larvae were transported to a laboratory at the Smithsonian Tropical Research Institute in Gamboa and maintained at ambient photoperiod and temperature separately in plastic food containers $(473 \mathrm{ml})$ with plastic mesh for aeration and moistened filter paper. Each cup was supplied daily with a fresh, intact M. umbellata leaf. Upon reaching the fourth instar, wet and dry weights of larvae and shields $(N=34)$ were taken to the nearest $10^{-4} \mathrm{~g}$. Shields for chemical analysis were harvested and stored without solvent at $-32^{\circ} \mathrm{C}$. To focus on resistance due to shields alone, we eliminated confounding escape and shield waving behaviors by using freshly killed (by freezing) fourth instar $C$. alternans larvae. Larvae were stored individually in $2 \mathrm{ml}$ glass vials at $-2{ }^{\circ} \mathrm{C}$ for later use in bioassay experiments.

Separation and Identification of Active Compounds in the Shield Extract Liquid chromatography-mass spectrometry (LC-MS) was used to identify the constituents of the methanolic extract. We dissolved $100 \mathrm{mg}$ of shield material in $2 \mathrm{ml} \mathrm{MeOH}$, sonicated it for $5 \mathrm{~min}$, and then centrifuged the sample for $20 \mathrm{~min}$. The supernatant was placed in a gas chromatography (GC) vial and diluted 1:10, of which $10 \mu 1$ were injected into an Agilent HP 1100 high-performance liquid chromatography (HPLC) equipped with a Lichrosphere $\mathrm{RP} 18,5 \mu \mathrm{m}$ column. A water- $\mathrm{CH}_{3} \mathrm{CN}$ gradient with a flow rate of $1 \mathrm{ml} \mathrm{min}{ }^{-1}$ started at $70: 30 \mathrm{CH}_{3} \mathrm{CN} / \mathrm{H}_{2} \mathrm{O}(v / v)$ from $0-30 \mathrm{~min}$ to $100 \% \mathrm{CH}_{3} \mathrm{CN}$ up to $45 \mathrm{~min}$ hold at $100 \%$ $\mathrm{CH}_{3} \mathrm{CN}$ and then $45-45.5$ min back to $70: 30 \% \mathrm{CH}_{3} \mathrm{CN} /$ $\mathrm{H}_{2} \mathrm{O}(v / v)$ for $60 \mathrm{~min}$. The sample was analyzed by a Thermo Finnigan LCQ with a positive atmospheric pressure chemical ionization source, in full scan mode with a vaporizer temperature of $450^{\circ} \mathrm{C}$, a capillary temperature of $145^{\circ} \mathrm{C}$, a sheath gas flow rate of 60 arbitrary units, and an auxiliary gas flow of 15 arbitrary units. The discharge current was $5 \mathrm{eV}$, the capillary voltage $10 \mathrm{~V}$, and the tube lens offset was $20 \mathrm{~V}$.

Verification of Compound Bioactivity Based on the LC-MS results, a commercial pheophorbide $a(\mathrm{Ph} a)$ standard (Wako 163-11171) was applied to shields to measure repellence or deterrence in field bioassays. One day before a bioassay experiment, larvae were removed from storage and their shields detached by placing fine forceps between the tines of the caudal process and gently lifting the shield away from the larva. Larval bodies were returned to refrigeration at $0^{\circ} \mathrm{C}$.

Shields were randomly assigned to either a $\mathrm{Ph} a$ treatment group, to an intact shield "control" group, or to a solvent control group. The shield groups receiving $\mathrm{Ph} a$ test solutions were subjected to the following leaching treatment to remove metabolites: $200 \mathrm{ml}$ of $\mathrm{MeOH}$ for $45 \mathrm{~min}$ with agitation every $5 \mathrm{~min}$, followed by $400 \mathrm{ml}$ of
$\mathrm{H}_{2} \mathrm{O}$ for $45 \mathrm{~min}$ with agitation every $5 \mathrm{~min}$. Shields were dried under a fan for $1 \mathrm{~h}$ and then placed individually in $2 \mathrm{ml}$ glass vials. From a $1 \mathrm{mg} \mathrm{ml}^{-1}$ methanolic stock solution of pheophorbide $a$, dilutions were made to obtain $1,3,5$, or $10 \mu \mathrm{g}$ test dilutions $(N=32,36,34$, and 32 shields, respectively). For example, to apply $1 \mu \mathrm{g}$ of Ph $a$ to a shield, $40 \mu 1$ of the stock solution was placed in a vial to yield $40 \mu \mathrm{g}$, which were then dissolved in $2 \mathrm{ml}$ of $\mathrm{MeOH}$. From this solution, $50 \mu \mathrm{l}(1 \mu \mathrm{g})$ were topically applied to each shield. Shields were dried under a fan for $12 \mathrm{~h}$. Each shield was reattached to the caudal process of a larva by using a rapid setting, fumeless, water-insoluble craft glue $\left(\mathrm{DAP}^{\circledR}\right)$, and allowed to dry $2 \mathrm{~h}$ before bioassays began. Shields in the solvent control group $(N=41)$ were leached and dried as per above, and each shield received $50 \mu \mathrm{l}$ of $\mathrm{MeOH}$. Shields were dried $2 \mathrm{~h}$ before bioassays began. Unleached, intact controls $(N=32)$ consisted of only the shield removal and reattachment manipulations described above.

Bioassay Protocol Field bioassays were conducted near Gamboa in September 2007, between 8:30 A.M. and 12:30 P.M. We used a common and aggressively recruiting generalist predator, the ant Azteca lacrymosa Forel (Hymenoptera: Formicidae: Dolichoderinae), in the bioassays. Voucher specimens of host, beetle, and ant species are deposited in the herbarium and insect collection of Smithsonian Tropical Research Institute, Panamá.

Bioassay experiments were conducted on a raised, $45 \times$ $60 \times 2 \mathrm{~cm}$ platform that was touching the bole of a tree with an A. lacrymosa nest (Fig. 1b). Vines and fallen branches with active ant trails were connected to the platform, and these formed clearly defined avenues across the platform's surface, which varied from four to seven daily. To verify foraging motivation in the ants, the platform was baited with tuna and sugar water $1 \mathrm{~h}$ prior to experiments. If baits were removed within the hour, an experiment was conducted with one of the treatments. Each bioassay trial consisted of the presentation of a single shielded larva. With soft forceps, we placed the larva $1 \mathrm{~cm}$ from an active foraging trail on the platform. A trial began after the first ant antennated the larva. Each bioassay trial lasted $5 \mathrm{~min}$, or until a larva was captured. A larva was deemed captured when the ants carried it $\geq 1 \mathrm{~cm}$ sideways or backwards, and we recorded this interval as the time from first contact to capture. Individual trials were separated from one another by 3 to $5 \mathrm{~min}$ and were conducted along different trails on the platform separated from one another by at least $30 \mathrm{~cm}$. These time delays and variable locations minimized recruitment interactions across assays to insure that different ants were involved in each bioassay trial. Trials of one of the treatment types or of intact larvae were interspersed randomly with trials of the solvent controls. 
Fig. 2 Chromatographic separation and identification of chlorophyll catabolites from fecal shields of C. alternans. a LCMS profile of the methanolic extract of larval shields (straight line) and the pheophorbide $a$ standard (dotted line). The two peaks for Pha represent epimeric esters of ring $\mathrm{V}$ (Smith et al. 1985), $\mathrm{Ph} a\left(\mathrm{R}=\mathrm{CH}_{3}\right), \mathrm{Ph} b$ $(\mathrm{R}=\mathrm{CHO})$, (asterisks) unknown compounds. b UV spectra of $\mathrm{Ph} a$ (straight line) and $\mathrm{Ph} b$ (dotted line)
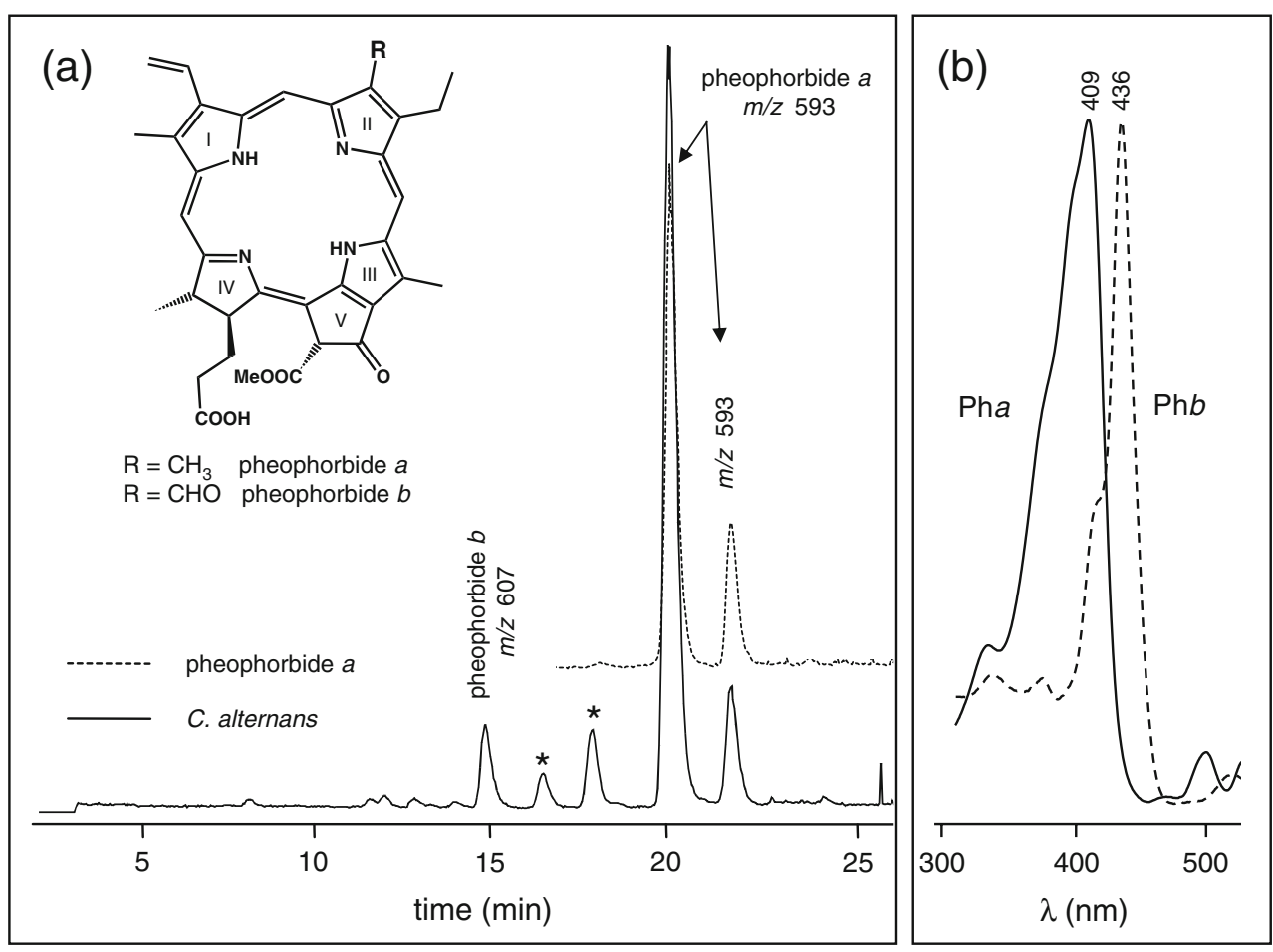

Quantification of Pheophorbide a For direct quantification of the components in the methanolic extract, shields (ca. $50 \mathrm{mg}$ ) were placed in methanol $(2 \mathrm{ml}$ ) and sonified for $2 \mathrm{~min}$. Solids were deposited by centrifugation $(20 \mathrm{~min}$ at $20 \times \mathrm{g})$ and $10 \mu \mathrm{l}$ of the supernatant, a clear liquid, were diluted with the tenfold volume of methanol followed by analysis by HPLC-MS without further purification.

To quantify pheophorbide $a$ in shields, a calibration curve (peak area vs. concentration) was calculated by using reversed-phase HPLC-MS and the commercial Pha standard at concentrations of $0.01,0.10,1.0$, and $2.0 \mu \mathrm{g} \mathrm{ml}^{-1}$ $\mathrm{MeOH}$ under the same conditions used for the shield samples. The pheophorbide $a$ standard gave two peaks, (84:16, see Fig. 2a) corresponding to the stereoisomers in ring $\mathrm{V}$ of $\mathrm{Ph} a$, whose areas were added together and averaged $\left(y=671,095,720.3552 x ; R^{2}=0.9947\right)$.

Statistical Analyses We examined larval capture times in the bioassay by using a partial regression failure-time approach, the Cox proportional hazard model (PROC TPHREG; SAS 2004). In contrast to classical methods, such as analysis of variance (ANOVA) that compare either the total number of captures at the end of the experimental time interval or the average capture time among treatment groups, failure-time methods compare the distributions of capture times throughout the entire bioassay period. Times to the occurrence of an event (e.g., capture of a larva by ants) typically do not meet the distributional assumptions required by traditional parametric approaches. In addition, many of the trials ended before a capture event was recorded (i.e., right-censored data), and the ultimate fate of the larva beyond the bioassay interval was unknown. Due to the exclusion of such right-censored events, failtime approaches are more appropriate than ANOVA or frequency-based methods to detect time-dependant changes in resistance.

Capture functions were compared by using the Wilcoxon's signed ranks test followed by pair-wise multiple comparisons to determine specific differences between treatment groups (Kalbfleisch and Prentice 1980). Significance levels were corrected with the sequential Bonferroni technique (DunnSidák method; Sokal and Rohlf 1995). This method is less conservative than the standard Bonferroni technique but ensures that an appropriate experiment-wise error rate $(\alpha=0.05)$ is maintained. Predation rates were graphed using the life table approach (PROC LIFETEST; SAS 2004).

\section{Results}

HPLC-MS of Shield Extract The LC-MS of a methanolic extract from $C$. alternans shields revealed two peaks at $20.18 \mathrm{~min}(84 \%)$ and $21.97 \mathrm{~min}(16 \%)$ both with a molecular ion at $\mathrm{m} / \mathrm{z} 593.4$ (Fig. 2a). Both peaks had a strong UV absorption around $409 \mathrm{~nm}$ accompanied by a smaller absorption at $666 \mathrm{~nm}$ (Fig. 2b). These data suggested the presence of a porphyrin-type compound, such as pheophorbide $a(\mathrm{Ph} a)$, the major catabolite of chlorophyll $a$ in plants. Injection of authentic Pha generated 
the same two peaks at $20.10 \mathrm{~min}(84 \%)$ and $21.89 \mathrm{~min}$ $(16 \%)$ in a similar ratio (Fig. 2a). Thus, on the basis of spectral (MS, UV, ${ }^{1} \mathrm{H}$ and ${ }^{13} \mathrm{C}$ nuclear magnetic resonance; see Smith et al. 1985) and chromatographic coincidence, the two major peaks at $\mathrm{m} / \mathrm{z} 593$ could be attributed to the chlorophyll catabolite, $\mathrm{Ph} a\left(\mathrm{C}_{35} \mathrm{H}_{36} \mathrm{~N}_{4} \mathrm{O}_{5}\right)$.

The two 593 peaks are formed by the separation of the epimeric esters in ring $\mathrm{V}$, which resulted from the facile enolization of the $\beta$-keto ester into a conjugated system followed by reprotonation. Due to the presence of a second chiral center in ring III, a mixture of diastereomers is formed that readily separates on the chromatographic column. In addition to the two Pha peaks, we identified a minor signal for pheophorbide $b(\mathrm{Ph} b)$ at $14.79 \mathrm{~min}$. Pheophorbide $b$ is characterized by a molecular ion at $\mathrm{m} / \mathrm{z}$ 607 and a long-wave UV maximum at $436 \mathrm{~nm}$, which is due to the extended chromophore with the aldehyde group in ring II (Fig. 2a; $\mathrm{R}=\mathrm{CHO})$. The signals at $16.4 \mathrm{~min}(\mathrm{~m} / \mathrm{z}$ $609)$ and $17.8 \mathrm{~min}(\mathrm{~m} / \mathrm{z} 625)$ could not be identified (denoted *; Fig. 2a). These peaks most likely represent other, still unknown chlorophyll catabolites, since their UV spectra also exhibited maxima at 410 and $400 \mathrm{~nm}$, respectively. The natural concentration of $\mathrm{Ph} a$ in $C$. alternans was determined to be $2.38 \mu \mathrm{g} \mathrm{mg}^{-1}$ of fecal shield. An individual shield had a mean $( \pm$ SE) dry weight of $64( \pm 4) \mathrm{mg}(N=34)$. The naturally relevant $\mathrm{Ph} a$ shield concentration was, therefore, estimated to be $152.3 \pm 9 \mu \mathrm{g}$ per intact shield.
Bioassay of Pha-Loaded Shields The regression coefficients derived from the Cox proportional hazard model for shields augmented with 3,5 , and $10 \mu \mathrm{g}$ concentrations of $\mathrm{Ph} a$ resisted capture significantly longer than did the solventleached controls (Fig. 3; $P=0.05$ after Bonferroni correction for multiple pair-wise comparisons; see "Materials and Methods"). Larvae with shields enhanced with $5 \mu \mathrm{g} \mathrm{Ph} a$ withstood capture at a slightly lower but not significantly different rate than did larvae with intact shields (Fig. 3). Capture rates for shields with $\mathrm{Ph} a$ concentrations of $10 \mu \mathrm{g}$ did not differ significantly from intact shields $(P>0.05)$. Shield concentrations of $1 \mu \mathrm{g}$ of $\mathrm{Ph} a$ did not differ from solvent control shields $(P>0.05)$.

Most of the ants first coming into contact with a treated larva appeared to hesitate, retreat a short distance with their abdomens raised, and then to re-contact the larvae by antennation or by touching (not biting) with open mandibles. Within the first minute of many bioassay trials (77/ 166) with intact and Pha-treated larval shields, the first ants to contact a treatment larva either retreated a short distance and began antennal grooming, or they repeatedly ran in circles nearby the larva, only to return briefly without eliciting recruits or seizing the larva. In some trials (17/ 166), ants making initial contact with a Pha-treated larva withdrew directly and never returned or recruited other ants. All of these behaviors created delays and indicated a reluctance to seize a larva. Such hesitancy contributed to

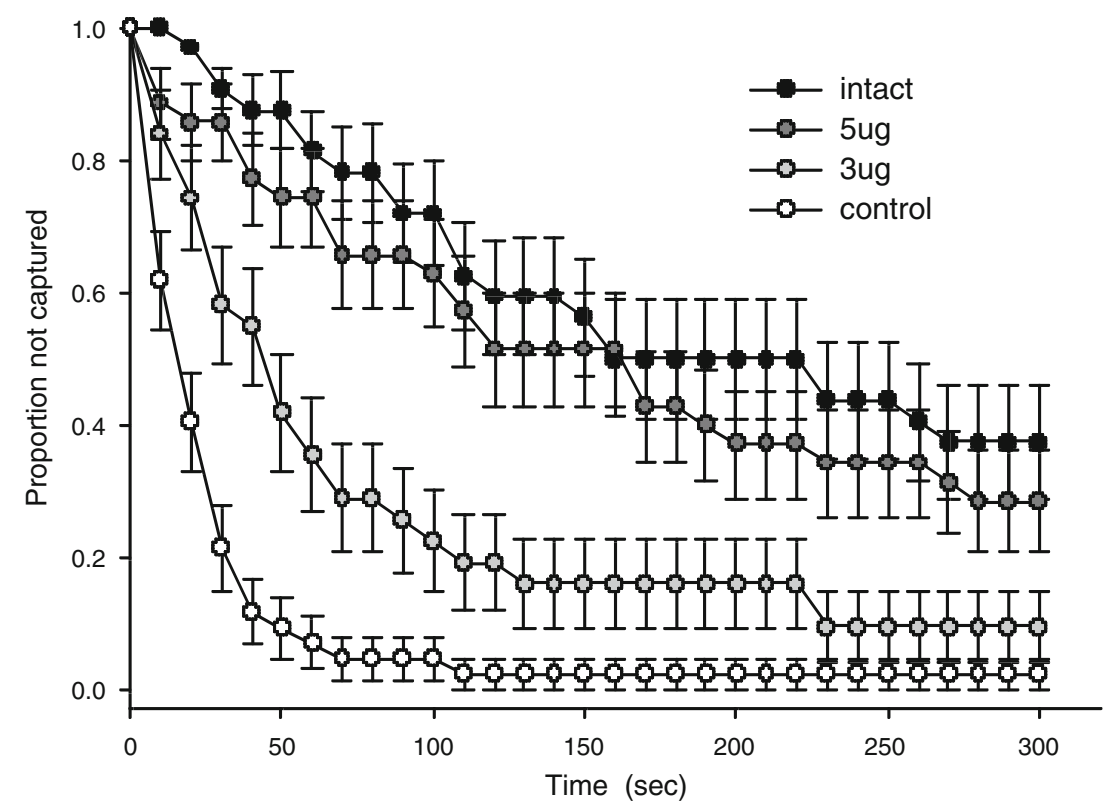

Fig. 3 Survival curves showing capture rates of $C$. alternans larvae with intact, pheophorbide $a$-augmented, or methanol control shields in the Azteca ant bioassay. Leached shields were enhanced with either $3 \mu \mathrm{g} / \mathrm{shield}$ (grey circles) or $5 \mu \mathrm{g} / \mathrm{shield}$ (dark grey circles) concentrations of pheophorbide $a$. Larval controls (open circles) had their shields leached (methanol and water), modified with $50 \mu \mathrm{l}$ of $\mathrm{MeOH}$, and then reattached. Intact shields (solid circles) were removed and reattached to larvae without leaching or the addition of any substances. Data from the $1 \mu \mathrm{g}$ and $10 \mu \mathrm{g}$ additions of Ph $a$ were excluded for the sake of clarity. The former treatment was not different from zero $\mathrm{Ph} a$, and the latter treatment did not differ from larvae with intact shields. Bars are the standard error of the life table estimate. Samples sizes: $3 \mu \mathrm{g}=36,5 \mu \mathrm{g}=34$, solvent control $=41$, and intact shields $=32$ 
the significantly longer capture times for both the $\mathrm{Ph} a$ and intact shield treatments. None of these behaviors were observed with the solvent-leached treatments.

\section{Discussion}

Our findings demonstrate that the shields of $C$. alternans larvae function mainly as deterrent chemical defenses. Ants avoid larvae only after coming into direct contact with them. On the basis of spectral and structural evidence, we identified actively deterrent compounds that reside in the methanolic extract of $C$. alternans shields as the chlorophyll catabolites, pheophorbide $a$, and pheophorbide $b$. The major metabolite, $\mathrm{Ph} a$, with approximately $78 \%$ of total chlorophyll catabolites, exhibited significant deterrence against $A$. lacrymosa ants in the field bioassay. Judging from the behavioral responses of A. lacrymosa, shields derive their deterrent activity by contact irritancy and then by eliciting disorientation.

Pheophorbide $a$ is potent. Deterrence was detected at only $1 \%$ or $2 \%$ of its natural shield concentration, which is on the order of $100 \mu \mathrm{g}$ per shield. At $4 \%$ of its natural concentration $(5 \mu \mathrm{g}), \mathrm{Ph} a$ appears to be responsible for over $90 \%$ of shield deterrence measured in this type of bioassay against this particular predatory enemy.

The origin of pheophorbide shield derivatives represents a two-step sequestration strategy, consisting of the assimilation and modification of the host plant precursor, chlorophyll, by the insect. Pheophorbide $a$ and $\mathrm{Ph} b$ are most likely produced in the beetle's digestive system from ingested chlorophyll $a$ and $b$. Probably no specialized enzymes, besides the ubiquitous lipases and esterases of the gut, are needed to remove the phytol side chain and the central magnesium ion (Kräutler et al. 1997). Pheophorbide $a$, thus, has a unique role in ecology: it is the first time that a chlorophyll degradation product has been assigned an interspecific, non-nutritive defense function, which may have implications for the wider occurrence of chlorophyll degradation products in other defense systems.

Although the vast majority of reports about its activity stem from the mammal literature, Ph $a$ appears to have a wide range of activities, including anti-tumor, immunosuppressant, and bio-toxic properties. For example, exposure of human lymphoid leukemia Molt 4B cells to Pha led both to growth inhibition and to the induction of programmed cell death (apoptosis; Hibasami et al. 2000; Chan et al. 2006). Chee et al. (2005) demonstrated that $\mathrm{Ph} a$ and its derivatives exhibit photocytotoxic activity in human leukemia and oral squamous carcinoma cell lines. As a possible therapeutic, $\mathrm{Ph} a$ isolated from Psychotria acuminata (Rubiaceae) inactivated cell surface receptors and contributed not only to the antitumor effects of photodynamic therapy but also to systematic immuno-suppression (Glinski et al. 1995). As a possible insect toxin, $\mathrm{Ph} a$ was shown to inhibit cholesterol acyltransferase, an enzyme necessary for the assimilation of the plant sterols that are required by insects to synthesize developmental hormones such as ecdysone (Song et al. 2002). When photosensitized, $\mathrm{Ph} a$ disrupted mitochondrial electron transport (Kim et al. 2004). Such findings suggest that bioassay experiments conducted in darkness may yield different results. In this connection, it is noteworthy that $C$. alternans larvae feed out of direct sunlight on the abaxial leaf surface. We do not know how the insect protects itself from the effects of Pha. Perhaps the polarity of the molecule, although moderate, contributes to its compartmentalization in the gut, thus insulating it from vulnerable tissues. In favor of this idea is the fact that there is a free carboxyl group that might occur as a salt if the gut $\mathrm{pH}$ were alkaline. At least for Lepidoptera, where the foregut is extremely alkaline, with a $\mathrm{pH}$ of about 10.5 , there are conditions favorable for salt formation (Funke et al. 2008). Future research on events in the gut is required to clarify this question.

Most chemically enhanced shield defenses examined so far rely mainly on host-derived secondary metabolites for their repellence or deterrence (see Müller and Hilker 2004). For instance, the Cordia-feeding Eurypedus nigrosignata and Coptocycla leprosa have potent chemical defenses based on host-derived terpenes (Gómez 1997; Gómez et al. 1999). However, there are a few reports of defenses in larval herbivores attributed to derivatives of co-opted primary compounds, such as chlorophyll or fatty acids. The shields of the Solanum-feeding tortoise beetle, Plagiometriona clavata, for instance, incorporate both primary host metabolites phytol, hexadecanoic, linolenic and oleic acids, and secondary metabolites like saponins and steroidal alkaloids that mount an effective deterrent defense (Morton and Vencl 1998; Vencl and Morton 1999; Vencl et al. 1999).

By intentionally removing behavior from the defense equation, this study focused on compounds that were separated with LC-MS, and the main peaks detected turned out to be potent in the Azteca ant bioassay. Since immobilized larvae with intact shields used in this study were not completely protected from Azteca ants-60\% were taken within the 5-min bioassay timeframe-there may be more to the Chelymorpha defense, namely, (1) other shield chemicals, and (2) evasive behaviors and shield waving. First, from a theoretical standpoint, an herbivore that is threatened by many different enemies should incorporate a variety of different defensive compounds, rather than relying on a single repellent or deterrent, which may have limited efficacy against a broad spectrum of enemies. Even assuming that Azteca presently is and has been the major larval enemy, the possibility exists that there are other shield compounds, which may target different 
enemies. Interestingly, phytol, a chlorophyll accessory molecule, along with a restricted suite of fatty acids, all of which are demonstrably deterrent (see references above), were detected by GC-MS examination of the hexane extract of $C$. alternans' shields (unpublished data). Future bioassay work will be required to determine if these ancillary compounds add to $C$. alternans' shield defense against Azteca or perhaps other enemies as well. Second, a live larva with intact behavior should survive this bioassay significantly better. For instance, a previous study that compared live Acromis sparsa and C. alternans larvae feeding on the same host (thereby equalizing chemical input to their shields) found that both species were equally resistant to Azteca ant predation (Vencl et al. 2005). Compared to A. sparsa however, C. alternans larvae responded to ant attack with increased defensive behaviors (escape and shield-waving). Moreover, once C. alternans larvae were deprived of such behavioral tactics (by freezing), they became significantly more vulnerable to predation compared to their equally immobilized counterparts. The resistance of live C. alternans, thus, appears due to higher levels of behavioral defenses. The ability to flee quickly, to tightly grip the substrate, and to reduce their apparency by hiding are important defense tactics for many Cassidinae species as well as for other exophytic larvae, such as those of the Lepidoptera (Stamp and Bowers 1992; Gentry and Dyer 2002; Zalucki et al. 2002). Future avenues of research should assess the importance of chemistry in relation to other defenses to first evaluate their separate contributions and then their possible interactions that may enhance overall survival in a nonlinear fashion.

Over the past 50 years, numerous studies have documented the role sequestered plant secondary metabolites play in herbivorous insect defenses against predators and parasitoids (Whitman et al. 1990; Trigo 2000; Nishida 2002). Given their astonishing diversity in plants, it is surprising that the majority of known defensive phytochemicals utilized by larval herbivores is restricted largely to the derivatives of just three secondary compound classes: phenolics, terpenes, and nitrogen-containing compounds, such as alkaloids and amino acids (Harborne et al. 1999; reviewed by Nishida 2002). This discrepancy may be due partly to an insufficient survey of larval defenses, especially of fore and aft discharges, many of which may rely on the assimilated secondary metabolites, and as demonstrated here, the degradation products of host-derived primary precursors. Erstwhile nutrients like $\mathrm{Ph} a$, when activated and positioned strategically, may represent an economical and less dangerous alternative to sequestration of potentially auto-toxic or costly endogenously synthesized defense compounds. The widespread correlation of elaborate morphological annexes, fecal retention behaviors with appropriated host plant chemistry, strongly supports the idea that the recurrence of these traits constitutes an under-recognized, multi-trait integrated phenotype. It is conceivable that such trait assemblages may have been responsible for the astonishing success of the limited number of herbivore lineages whose exophytic larvae feed in the dangerous leaf adaptive precinct.

Acknowledgments We thank N. Rivas, Y. Lakey, and L. Cabilla Rios for laboratory support and technical assistance. An anonymous review and D. Windsor provided many useful insights. Experiments, sample exportation, and specimen collection were done under permits issued by the Authoridad Nacional del Ambiente de Panamá (ANAM). This is contribution \#1165 from the graduate program of the Department of Ecology and Evolution at Stony Brook University. This research was supported by the US National Science Foundation IBN \#108213 to FVV.

\section{References}

Chan, J. Y., Tang, P. M., Hon, P. M., Au, S. W., Tsui, S. K., Waye, M. M., Kong, S. K., MaK, T. C., and FunG, K. P. 2006. Pheophorbide a, a major antitumor component purified from Scutellaria barbata, induces apoptosis in human hepatocellular carcinoma cells. Planta Medica 72:28-33.

Chee, C., LeE, H. B., ONG, H. C., and Ho, A. S. 2005. Photocytotoxic pheophorbide-related compounds from Aglaonema simplex. Chemistry and Biodiversity 2:1648-1655.

EISNER, T., and EISNER, M. 2000. Defensive use of a fecal thatch by a beetle larva (Hemisphaerota cyanea). Proceedings of the National Academy of Sciences of the United States of America 97:2632-2636.

Eisner, T., TASSEl, E., and CARrel, J. E. 1967. Defensive use of "fecal shield" by a beetle larva. Science 158:1471-1473.

EVANS, D. L., and SCHMIDT, J. O. 1991. Insect Defenses. Adaptive Mechanisms and Strategies of Prey and Predators. State University of New York Press, Albany, NY.

FUNKE, M., BÜCHLER, R., MAHOBIA, V., SCHNEEBERG, A., RAMM, M., and Boland, W. 2008. Rapid hydrolysis of quorum-sensing molecules in the gut of Lepidopteran larvae. ChemBioChem 9:1953-1959.

GENTRY, G. L., and DYER, L. A. 2002. On the conditional nature of Neotropical caterpillar defenses against their natural enemies. Ecology 83:3108-3119.

Glinski, J. A., DAVID, E., WARren, T. C., HANSEN, G., LeONARD, S. F., Pitner, P., Pav, S., Arvigo, R., Balick, M. J., Panti, E., and GROB, P. M. 1995. Inactivation of cell surface receptors by pheophorbide a, a green pigment isolated from Psychotria acuminata. Photochem. Photobiol. 62:144-150.

GómEZ, N. E. Q. 1997. The fecal shield of larvae of tortoise beetles (Cassidinae:Chysomelidae): a role for chemical defense using plant-derived secondary compounds. Ph. D. dissertation, Technischen Universität Carolo-Wilhelmina, Braunschweig.

Gómez, N. E., WitTe, L., and Hartmann, T. 1999. Chemical defense in a tortoise beetle: essential oil composition of larval fecal shields of Eurypedus nigrosignata and its host plant Cordia curassavica. J. Chem. Ecol. 25:1007-1027.

GRoss, P. 1993. Insect behavioral and morphological defenses against parasitoids. Annu. Rev. Entomol. 38:251-273.

Harborne, J. B., BAXTer, H., and Moss, G. P. 1999. Phytochemical Dictionary: A Handbook of Bioactive Compounds from Plants. Taylor \& Francis, London.

HibASAMI, H., KYOKON, M., OHWAKI, S., KATSUZAKI, H., IMAI, K., NAKAGAWA, M., IshII, Y., and KomIYA, T. 2000. Pheophorbide a, 
a moiety of chlorophyll a, induces apoptosis in human lymphoid leukemia Molt 4B cells. Int. J. Mol. Med. 6:277-279.

HunTER, A. F. 2000. Gregariousness and repellent defense in the survival of phytophagous insects. Oikos 91:213-224.

KalbfleisCH, J. D., and Prentice, R. L. 1980. The Statistical Analysis of Failure-Time Data.. Wiley, NY, USA.

KIM, C. S., LEE, C. H., LEE, P. H., and HAN, S. 2004. Inactivation of mitochondrial electron transport by photosensitization of a pheophorbide a derivative. Mol. Cells 17:2347-352.

KräUtler, B., MüHLECKER, W., ANDERl, M., and Gerlach, B. 1997. 101. Breakdown of Chlorophyll: partial synthesis of a putative intermediary catabolite. Helveticca Chimica Acta 80:1355-1362.

Morton, T. C., and Vencl, F. V. 1998. Larval beetles (Chrysomelidae: Criocerinae) form defense from recycled host compounds discharged as fecal wastes. J. Chem. Ecol. 24:765-786.

MÜLleR, C., and HILKER, M. 2004. Ecologiccal relevance of fecal matter in Chrysolmelidae, pp. 693-708, in P. Jolivet, J. A. Satiago-Blay, and M. Schmitt (eds.). New Developments in the Biology of ChrysomelidaeSPB Academic Publishing, The Hague, The Netherlands.

NisHiDA, R. 2002. Sequestration of defensive substances from plants by Lepidoptera. Annu. Rev. Entomol. 47:57-92.

NogueIRA-DE-SÁ, F., and Trigo, J. R. 2002. Do fecal shields provide physical protection to larvae of the tortoise beetle Plagiometriona flavescens and Stolas chalybea against natural enemies? Entomol. Exp. Appl. 104:203-206.

Nogueira-De-SÁ, F., and Trigo, J. R. 2005. Faecal shield of the tortoise beetle Plagiometriona aff. flavescens (Chrysomelidae: Cassidinae) as chemically mediated defence against predators. $J$. Trop. Biol. 21:189-194.

OlmSTEAD, K. L., and DENNO, R. F. 1993. Effectiveness of tortoise beetle larval shields against different predator species. Ecology 74:1394-1405

Ruxton, G. D., Sherratt, T. N., and Speed, M. 2004. Avoiding Attack: The Evolutionary Ecology of Crypsis, Warning Signals and Mimicry.. Oxford University Press, Oxford, UK.
SAS, 2004. ver. 9. The SAS Institute. Cary, North Carolina, U. S. A.

Smith, K. M., GofF, D. A., and Simpson, D. J. 1985. Mesosubstitution of chlorophyll derivatives - direct route for transformation of bacteriopheophorbides- $d$ into bacteriopheophorbides- $c$. Am. Chem. Soc. 107:4946-4954.

SOKAL, R. R., and RoHLF, F. J. 1995. Biometry. Freeman and Co, New York, USA.

Song, H., Rho, M., Lee, S. W., Kwon, O. E., Chang, Y., Lee, H. S., and KIM, Y. 2002. Isolation of Acyl-CoA:cholesterol acyltransferase inhibitor from Persicaria vulgaris. Planta Medica 68:845-847.

STAMP, N. E., and Bowers, M. D. 1992. Behavior of specialist and generalist caterpillars on plantain (Plantago lanceolata). Ecol. Entomol. 17:273-279.

StAmP, N. E., and CASEY, T. M. 1993. Caterpillars: Ecological and Evolutionary Constraints on Foraging. Chapman Hall, New York.

TRIGO, J. R. 2000. The chemistry of antipredator defense by secondary compounds in Neotropical Lepidoptera: facts, perspectives and caveats. J. Braz. Chem. Soc. 11:551-561.

VENCL, F. V., and MoRTON, T. C. 1999. Macroevolutionary aspects of larval shield defenses, pp. 217-238, in M. L. Cox (ed.). Advances in Chrysomelidae BiologyBackhuys Publishers, Leiden, The Netherlands.

Vencl, F. V., Morton, T. C., Mumma, R. O., and Schultz, J. C. 1999. The shield defense of a larval tortoise beetle. J. Chem. Ecol. 25:549-566.

Vencl, F. V., NOGUEIRA-dE-SA, ' F., ALLEN, B. J., Windsor, D. M., and FUTUYMA, D. J. 2005. Dietary specialization influences the efficacy of larval tortoise beetle shield defenses. Oecologia 145:409-414.

WeIss, M. R. 2006. Defecation behavior and ecology of insects. Annu. Rev. Entomol. 51:635-661.

WhitMAn, D. W., Blum, M. S., and Alsop, D. W. 1990. Allomones: Chemicals for defense, pp. 289-352, in D. L. Evans, and J. O. Schmidt (eds.). Insect defense: Adaptive Mechanisms and Strategies of Prey and PredatorsState University of New York Press, Albany, N. Y.

Zalucki, M. P., Clarke, A. R., and Malcolm, S. B. 2002. Ecology and behavior of first instar larval Lepidoptera. Annu. Rev. Entomol. 47:361-393. 